\title{
Arterial or venous free flaps for volar tissue defects of the proximal interphalangeal joint: A comparison of surgical outcomes
}

\author{
Min Suk Choi, Si Young, Roh, Sung Hoon Koh, Jin Soo Kim, Dong Chul Lee, Kyung Jin Lee, \\ Min Ki Hong
}

Department of Plastic and Reconstructive Surgery, Gwangmyeong Sungae Hospital, Gwangmyeong, Korea

\begin{abstract}
Background For volar soft tissue defects of the proximal interphalangeal (PIP) joint, free flaps are technically challenging, but have more esthetic and functional advantages than local or distant flaps. In this study, we compared the long-term surgical outcomes of arterial (hypothenar, thenar, or second toe plantar) and venous free flaps for volar defects of the PIP joint. Methods This was a single-center retrospective review of free flap coverage of volar defects between the distal interphalangeal and metacarpophalangeal joint from July 2010 to August 2019. Patients with severe crush injuries (degloving, tendon or bone defects, or comminuted/ intra-articular fractures), thumb injuries, multiple-joint and finger injuries, dorsal soft tissue defects, and defects $>6 \mathrm{~cm}$ in length were excluded from the study, as were those lost to follow-up within 6 months. Thirteen patients received arterial (hypothenar, thenar, or second toe plantar) free flaps and 12 received venous free flaps. Patients' age, follow-up period, PIP joint active range of motion (ROM), extension lag, grip-strength ratio of the injured to the uninjured hand, and Quick Disabilities of Arm, Shoulder \& Hand (QuickDASH) score were compared between the groups.

Results Arterial free flaps showed significantly higher PIP joint active ROM $(P=0.043)$ and lower extension lag $(P=0.035)$ than venous free flaps. The differences in flexion, grip strength, and QuickDASH scores were not statistically significant.

Conclusions The surgical outcomes of arterial free flaps were superior to those of venous free flaps for volar defects of the PIP joint.
\end{abstract}

Keywords Free tissue transfer flaps / Interphalangeal joint of finger / Reconstructive surgical procedure
Correspondence: Si Young Roh Department of Plastic and Reconstructive Surgery, Gwangmyeong Sungae Hospital, 36 Digital-ro, Gwangmyeong 14241, Korea

Tel: +82-2-2680-7637

Fax: +82-2-2615-7218

E-mail: psczero@gmail.com

This article was presented at the 36 th Korean Society for Surgery of the Hand Annual International Meeting on November 2-4, 2018, in Seoul, Korea.

Received: February 21, 2020 • Revised: July 8, 2020 • Accepted: July 22, 2020

pISSN: 2234-6163 • elSSN: 2234-6171 • https://doi.org/10.5999/aps.2020.00269・Arch Plast Surg 2020;47:451-459

\section{INTRODUCTION}

The volar skin and subcutaneous tissue of the fingers, except for the pulp, cover the neurovascular bundles, flexor tendon, and phalanx and play a major role in the movement of the interpha- langeal joints [1-4]. The proximal interphalangeal (PIP) joint of the digits has a large active and functional range of motion (ROM), making it an important factor in movements of the phalanges $[2,5,6]$. Therefore, defects on the volar surface of the PIP joint can result in impaired function of the hand. 
Several factors must be considered when covering a volar defect of the PIP joint. The skin has to be durable and supple to enable joint movement, and its color and texture should match that of the skin surrounding the defect for optimal esthetic results. Therefore, the surgical options for these defects include local or regional flaps, such as a cross-finger flap, dorsal metacarpal artery flap, or free tissue transfer [7-10]. Simple dressings and skin grafts are not feasible in this area due to the lack of the favorable factors mentioned above. Local or regional flaps are the treatment of choice, but if these are inadequate or unfeasible, microsurgical coverage should be considered [11].

Various reports have been published on free tissue transfer for the reconstruction of volar defects of the PIP joint $[1,4,12-15]$; however, no study has compared surgical outcomes between different types of free flaps. At our institution, we mainly use arterial free flaps, such as the second toe plantar free flap, thenar free flap, and hypothenar free flap, and arterialized venous free flaps from the forearm.

In this study, we compared the long-term surgical outcomes between arterial free flaps and venous free flaps for volar defects of the PIP joint.

\section{METHODS}

This study was a single-center retrospective review of medical records. The protocol received approval from our hospital's Ethics Review Board (IRB No. KIRB-2018-N-001), and patients provided informed consent for undergoing the procedures and use of their images. We reviewed the records of patients who received free flap coverage due to a volar defect of the PIP joint at our hospital from July 2010 to August 2019.

\section{Inclusion criteria}

The inclusion criteria were patients who (1) underwent free flap coverage of volar soft tissue on the PIP joint; (2) had follow-up data for more than 6 months after the operation; (3) and had visited our hospital from July 2010 to August 2019.

\section{Exclusion criteria}

The exclusion criteria were patients with (1) a defect on the thumb; (2) a multiple-finger injury; (3) a multiple-joint injury; (4) a severe crush injury, such as a degloving injury, tendon or bone defect, or comminuted/intra-articular fracture; or (5) a defect over $6 \mathrm{~cm}$ in length.

\section{Study design}

Twenty-five patients fulfilled the inclusion and exclusion criteria. We documented the patients' demographic data, follow-up period, PIP joint active ROM, degree of flexion, extension lag, grip-strength ratio of the injured to the uninjured hand (measured using a Jamar hand dynamometer; Patterson Medical, Warrenville, IL, USA) [16], and the Quick Disabilities of the Arm, Shoulder \& Hand (QuickDASH) score. Five surgeons performed the operations at various time points during the study period. We divided the patients into those who received arterial free flaps $(n=13)$ and those who received venous free flaps $(n=12)$.

Furthermore, we divided the patients according to the size of the flap (maximum length of flap $\leq 3 \mathrm{~cm}$ or $>3 \mathrm{~cm}$ ) and the presence of concomitant fractures or flexor tendon ruptures (excluding tendon or bone defects and comminuted/intra-articular fractures [including pulley ruptures]), as these are factors that might have affected the outcomes of surgery, and compared the surgical outcomes between these groups.

\section{Surgical techniques}

All patients underwent brachial plexus block, and spinal block was added for the second toe plantar free flap.

\section{Venous free flaps}

All the venous free flaps were elevated from the ipsilateral forearm because the forearm has simple and abundant venous connections, and the procedure can be done within the same operating field as the defect without additional anesthesia $[14,15]$. The flap was designed on the volar side of the mid-forearm to be approximately $10 \%$ to $20 \%$ larger than the defect to enable tension-free closure (Fig. 1). The desired thickness of the flap was achieved through suprafascial dissection [17]. The type of flap connection varied depending on the connection of the afferent and efferent veins. In our study, all flaps were elevated with one afferent and one efferent vein and arterialized either with arterial inflow and venous outflow (A-V-V type) or arterial flow-through (A-V-A type) [15,17]. All the donor sites were primarily closed.

\section{Second toe plantar free flaps}

These flaps were designed on the plantar side of the ipsilateral second toe based on the size of the defect. As with the venous free flaps, the second toe plantar free flaps were designed to be 10\%-20\% larger than the actual dimensions of the defect (Fig. 2 ). The medial plantar digital artery and nerve were elevated with the subcutaneous vein. Dorsal veins were preferred to plantar veins because of their larger diameter [18]. Dissection over the tendon sheath was extended proximally to acquire sufficient pedicle length. If a longer pedicle was needed to reconstruct the defect, the dissection was extended to the first metatarsal artery 


\section{Fig. 1. Venous free flap from mid-forearm}

The flap must be designed to be about 10\%-20\% larger than the defect for tension-free closure. Left white arrow, distal forearm; right white arrow, proximal forearm; green arrow, afferent vein; yellow arrow, efferent vein.

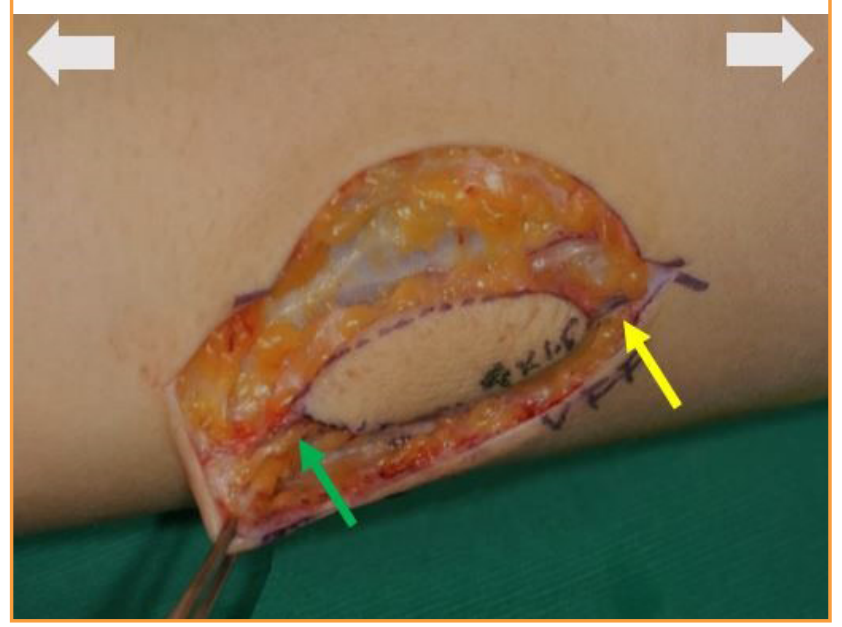

\section{Fig. 2. Second toe plantar free flap}

The digital artery and nerve were harvested together with the dorsal subcutaneous vein. Green arrow, digital artery, nerve; yellow arrow, dorsal subcutaneous vein.

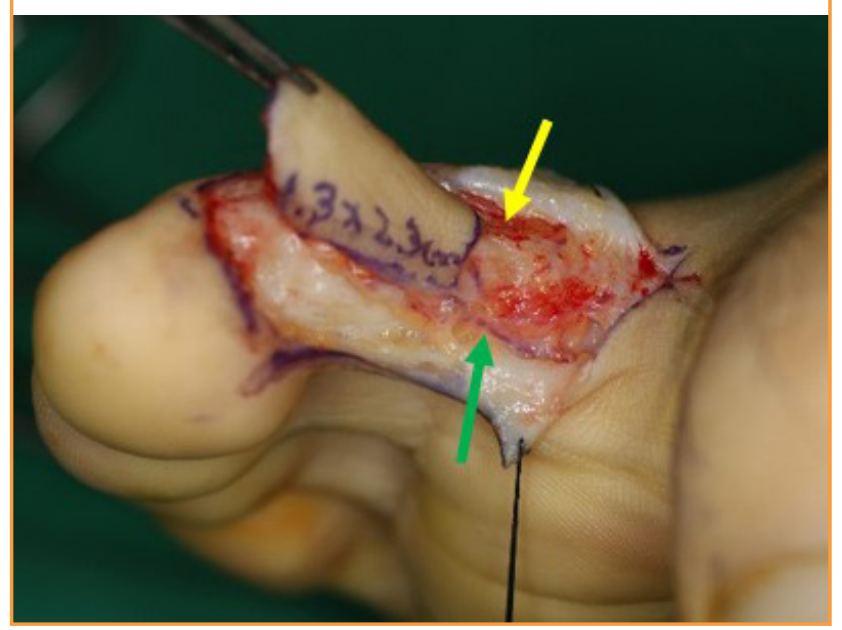

[1]. The free flap was inset into the defect, and the digital artery, nerve, and subcutaneous vein were anastomosed at the proximal phalanx base level, where the diameter of the plantar digital artery is similar that of the digital artery. In two of the three cases that received a second toe plantar free flap, the donor site could not be primarily closed, and a skin graft from the medial plantar side of the same foot was applied to the donor site.

\section{Thenar free flaps}

Thenar free flaps are supplied by the superficial palmar branch of the radial artery. Before designing the flap, the radial artery was

\section{Fig. 3. The radial artery superficial palmar branch flap}

The palmar cutaneous branch of the radial artery was identified near the scaphoid tubercle. Yellow arrow, superficial palmar branch of the radial artery.

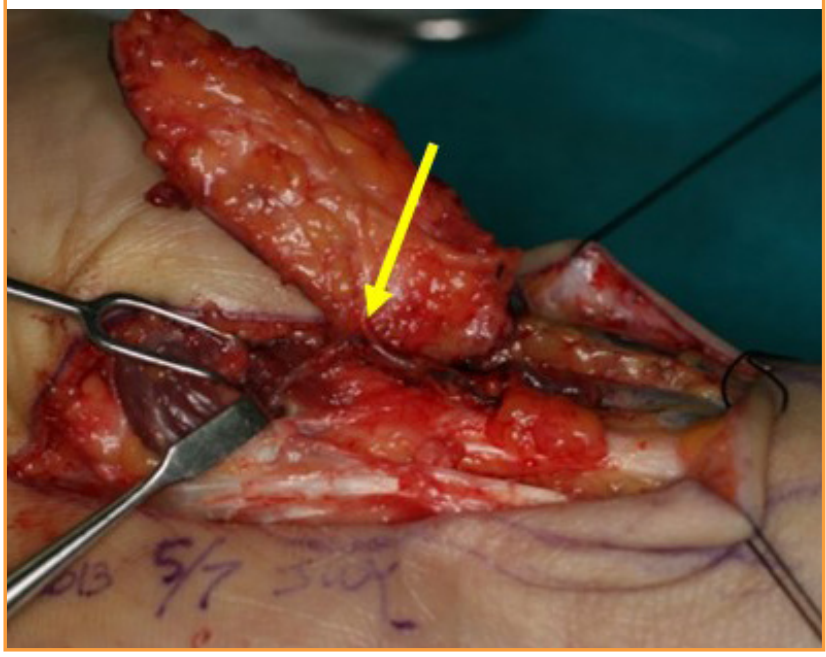

identified with a hand-held Doppler probe close to the styloid process $[4,12]$. From that location, the superficial palmar branch was traced to the scaphoid tubercle. Based on the size and shape of the defect, an elliptical flap design, $10 \%$ to $20 \%$ larger than the defect, was created from the thenar to the wrist crease and centered on the scaphoid tubercle (Fig. 3). After identification of the radial artery and superficial palmar branch, the flap was elevated with the perforating branch to the skin or fasciocutaneous area [12]. To match the diameter, the perforating branch was anastomosed to the digital artery at proximal phalanx base level, and the flap was connected to at least one subcutaneous vein. In three of the seven cases in our study, the flaps were innervated by the palmar cutaneous branch of the median nerve and anastomosed to the digital nerve [19]. Despite the large size of the donor site, primary closure was achieved owing to the presence of the redundant skin in this area.

\section{Hypothenar free flaps}

The hypothenar area has numerous skin perforators, and their constant location has been proven in several studies $[13,17,20]$. In accordance with the size and shape of the defect, the flap design was extended from the hypothenar eminence to the dorsoulnar skin. The dimensions of the flaps were also $10 \%-20 \%$ larger than the actual defect (Fig. 4). The incision started at the dorsal side of the flap. After identification of the dorsal subcutaneous vein, retrograde suprafascial dissection was performed along the course of the perforator. All the perforators in our study arose from the fourth common palmar digital artery. The flap was inset and anastomosed at the recipient site. As the pedi- 
cle diameters in the hypothenar free flaps were slightly smaller than those of the other arterial free flaps, the microvascular procedure was performed at the proximal phalanx shaft level. If complete coverage of the defect by the flap was infeasible, we harvested a skin graft near the flap donor site at the hypothenar eminence [13]. All donor sites were closed primarily.

\section{Statistical analysis}

Patient's demographic data, PIP joint active ROM, extension lag, degree of flexion, grip-strength ratio of the injured to the

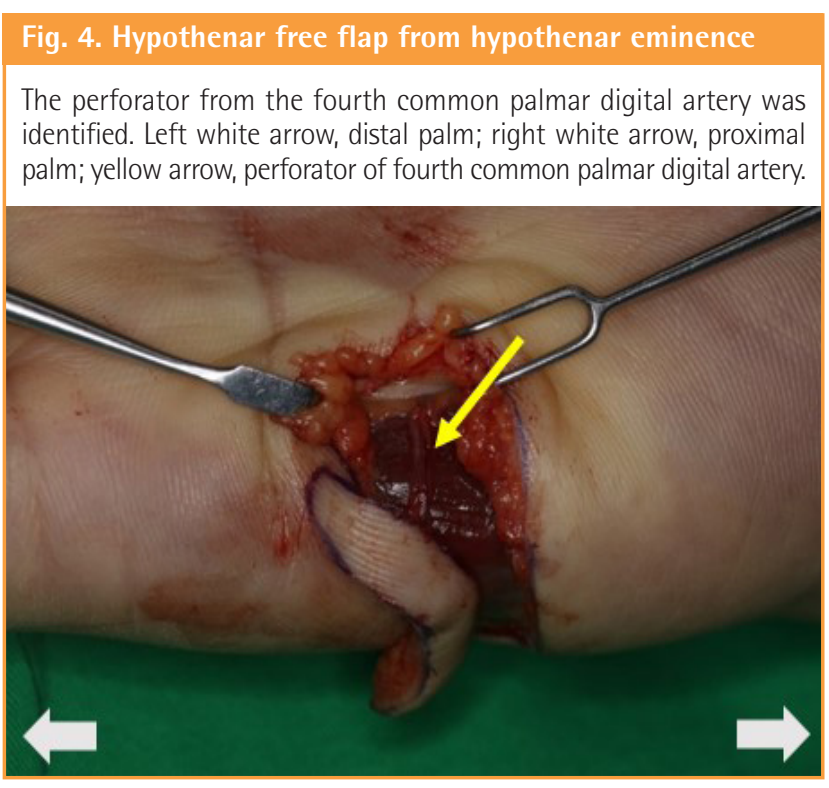

uninjured hand, and the QuickDASH score were compared between the arterial free flap and the venous free flap groups. Furthermore, the surgical outcomes were compared based on the size of the flap (maximum length of flap $\leq 3 \mathrm{~cm}$ or $>3 \mathrm{~cm}$ ) and the presence of concomitant fractures or flexor tendon ruptures (excluding tendon or bone defects and comminuted/intra-articular fractures [including pulley ruptures]). All statistical analyses were conducted with IBM SPSS Statistics for Windows, version 25.0 (IBM Corp., Armonk, NY, USA). The Student ttest and the Mann-Whitney $U$ test were used as appropriate, and a P-value of less than 0.05 was considered to indicate statistical significance.

\section{RESULTS}

Twenty-five patients were included, and their mean age was 36.8 years, with a range of 8 to 72 years. Of the 25 fingers that were treated ( 10 index, 2 middle, 8 ring, and 5 little fingers), 15 were on the right hand and 10 were on the left hand. All 25 patients were male. The mean follow-up period was 10.7 months.

The baseline characteristics and clinical outcomes of the patients in the arterial and the venous free flap groups are shown in Tables 1 and 2, respectively.

The average postoperative PIP joint active ROM was $73.9^{\circ}$ and $52.1^{\circ}$ in the arterial and venous free flap groups, respectively, and this difference was statistically significant $(P=0.043)$ (Table 3). There was also a significant difference in the PIP joint

Table 1. Demographic data and surgical outcomes of the patients receiving arterial free flaps $(n=13)$

\begin{tabular}{|c|c|c|c|c|c|c|c|c|c|c|c|c|}
\hline Patient No. & $\begin{array}{l}\text { Age } \\
(y r)\end{array}$ & Sex & $\begin{array}{l}\text { Side/ } \\
\text { finger }\end{array}$ & $\begin{array}{c}\text { Flap } \\
\text { size }(\mathrm{cm})\end{array}$ & $\begin{array}{c}\text { Presence } \\
\text { of } \\
\text { fracture }\end{array}$ & $\begin{array}{c}\text { Presence } \\
\text { of flexor } \\
\text { tendon } \\
\text { rupture }\end{array}$ & $\begin{array}{l}\text { Follow- } \\
\operatorname{up}_{\text {(mon) }}\end{array}$ & $\begin{array}{l}\text { PIP joint } \\
\text { flexion } \\
\left({ }^{\circ}\right)\end{array}$ & $\begin{array}{c}\text { PIP joint } \\
\text { extension } \\
\operatorname{lag}\left({ }^{\circ}\right)\end{array}$ & $\begin{array}{l}\text { PIP joint } \\
\text { ROM }\left(^{\circ}\right)\end{array}$ & $\begin{array}{l}\text { Grip } \\
\text { strength } \\
\text { ratio }^{\text {a) }}\end{array}$ & $\begin{array}{l}\text { QuickDASH } \\
\text { score }\end{array}$ \\
\hline \multicolumn{13}{|l|}{ Thenar free flap } \\
\hline 1 & 37 & M & $\mathrm{R} /$ index & $4.5 \times 2.0$ & Absent & Present & 6 & 60 & 0 & 65 & 0.83 & 25.0 \\
\hline 2 & 67 & M & $\mathrm{R} /$ index & $4.0 \times 2.0$ & Present & Absent & 9 & 60 & 5 & 55 & 0.87 & 34.1 \\
\hline 3 & 45 & M & $\mathrm{R} /$ ring & $6.0 \times 2.0$ & Present & Absent & 7 & 90 & 20 & 70 & 0.93 & 18.1 \\
\hline 4 & 26 & M & L/index & $6.0 \times 2.5$ & Present & Present & 13 & 95 & 0 & 95 & 0.90 & 11.3 \\
\hline 5 & 41 & M & $\mathrm{R} /$ index & $3.0 \times 2.0$ & Absent & Absent & 7 & 75 & 15 & 60 & 0.75 & 27.2 \\
\hline 6 & 29 & M & L/ring & $4.0 \times 2.0$ & Present & Present & 13 & 75 & 0 & 75 & 0.95 & 15.9 \\
\hline 7 & 57 & M & L/index & $2.5 \times 1.5$ & Absent & Absent & 6 & 80 & 10 & 70 & 0.90 & 31.8 \\
\hline \multicolumn{13}{|c|}{ Second toe plantar free flap } \\
\hline 8 & 19 & M & $\mathrm{R} /$ ring & $2.5 \times 1.5$ & Absent & Absent & 34 & 100 & 10 & 90 & 1.03 & 6.8 \\
\hline 9 & 43 & M & L/index & $2.0 \times 1.0$ & Present & Present & 10 & 75 & 15 & 60 & 0.75 & 34.1 \\
\hline 10 & 22 & M & $\mathrm{R} /$ ring & $2.5 \times 1.5$ & Absent & Present & 7 & 90 & 10 & 80 & 0.95 & 29.5 \\
\hline \multicolumn{13}{|c|}{ Hypothenar free flap } \\
\hline 11 & 35 & M & R/ring & $3.5 \times 1.0$ & Absent & Absent & 6 & 100 & 0 & 100 & 1.05 & 4.5 \\
\hline 12 & 44 & M & L/ring & $2.0 \times 1.0$ & Present & Absent & 7 & 80 & 10 & 70 & 0.85 & 31.8 \\
\hline 13 & 31 & M & $\mathrm{R} /$ middle & $4.0 \times 1.0$ & Present & Present & 6 & 80 & 10 & 70 & 0.90 & 29.5 \\
\hline Average & 39.2 & & & & & & 10.1 & 82.0 & 8.1 & 73.9 & 0.897 & 23.0 \\
\hline
\end{tabular}


Table 2. Demographic data and surgical outcomes of the patients receiving venous free flaps $(n=12)$

\begin{tabular}{|c|c|c|c|c|c|c|c|c|c|c|c|c|}
\hline $\begin{array}{l}\text { Patient } \\
\text { No. }\end{array}$ & $\begin{array}{l}\text { Age } \\
(y r)\end{array}$ & Sex & $\begin{array}{l}\text { Side/ } \\
\text { finger }\end{array}$ & $\begin{array}{c}\text { Flap size } \\
\text { (cm) }\end{array}$ & $\begin{array}{c}\text { Presence } \\
\text { of } \\
\text { fracture }\end{array}$ & $\begin{array}{l}\text { Presence of } \\
\text { flexor tendon } \\
\text { rupture }\end{array}$ & $\begin{array}{l}\text { Follow- } \\
\text { up } \\
\text { (mon) }\end{array}$ & $\begin{array}{l}\text { PIP joint } \\
\text { flexion } \\
\left(^{\circ}\right)\end{array}$ & $\begin{array}{l}\text { PIP joint } \\
\text { extension } \\
\operatorname{lag}\left({ }^{\circ}\right)\end{array}$ & $\begin{array}{l}\text { PIP joint } \\
\operatorname{ROM}\left({ }^{\circ}\right)\end{array}$ & $\begin{array}{l}\text { Grip } \\
\text { strength } \\
\text { ratio }^{\text {a) }}\end{array}$ & $\begin{array}{l}\text { QuickDASH } \\
\text { score }\end{array}$ \\
\hline 1 & 24 & $M$ & R/index & $4.0 \times 1.5$ & Present & Absent & 22 & 85 & 15 & 70 & 0.83 & 22.7 \\
\hline 2 & 19 & $M$ & R/index & $3.0 \times 1.0$ & Present & Absent & 27 & 75 & 15 & 60 & 0.95 & 20.4 \\
\hline 3 & 34 & M & R/little & $3.5 \times 1.0$ & Present & Absent & 6 & 45 & 15 & 30 & 0.80 & 43.2 \\
\hline 4 & 59 & M & L/little & $2.0 \times 1.0$ & Absent & Present & 26 & 70 & 0 & 70 & 0.85 & 22.7 \\
\hline 5 & 21 & M & L/ring & $4.5 \times 1.0$ & Present & Present & 6 & 30 & 15 & 15 & 0.60 & 61.4 \\
\hline 6 & 20 & M & R/little & $4.0 \times 2.0$ & Absent & Present & 10 & 70 & 40 & 30 & 0.87 & 45.4 \\
\hline 7 & 27 & M & L/index & $3.0 \times 1.0$ & Absent & Present & 7 & 80 & 15 & 65 & 0.85 & 27.2 \\
\hline 8 & 59 & M & R/ring & $2.5 \times 1.0$ & Absent & Absent & 6 & 95 & 10 & 85 & 0.83 & 15.9 \\
\hline 9 & 37 & M & $\mathrm{R} /$ middle & $1.5 \times 1.5$ & Absent & Absent & 6 & 85 & 25 & 60 & 0.90 & 25.0 \\
\hline 10 & 72 & M & L/index & $5.0 \times 2.0$ & Absent & Absent & 7 & 65 & 30 & 35 & 0.75 & 45.4 \\
\hline 11 & 35 & $M$ & R/little & $3.5 \times 1.5$ & Present & Present & 7 & 65 & 20 & 45 & 0.85 & 38.6 \\
\hline 12 & 8 & $M$ & L/little & $2.0 \times 1.5$ & Absent & Present & 6 & 80 & 20 & 60 & 0.90 & 22.7 \\
\hline Average & 33.4 & & & & & & 11.3 & 70.4 & 18.3 & 52.1 & 0.831 & 32.6 \\
\hline
\end{tabular}

Table 3. Comparison of the surgical outcomes between patients who received arterial free flaps $(n=13)$ and venous free flaps $(n=12)$

\begin{tabular}{|lccc|}
\hline Variable & $\begin{array}{c}\text { Arterial free } \\
\text { flap }\end{array}$ & $\begin{array}{c}\text { Venous free } \\
\text { flap }\end{array}$ & P-value ${ }^{\text {b) }}$ \\
\hline PIP joint ROM $\left(^{\circ}\right)$ & 73.9 & 52.1 & 0.043 \\
Extension lag $\left(^{\circ}\right)$ & 8.1 & 18.3 & 0.035 \\
Flexion $\left(^{\circ}\right)$ & 82.0 & 70.4 & 0.280 \\
Grip strength ratio & 0.897 & 0.831 & 0.515 \\
QuickDASH score & 23.0 & 32.6 & 0.423 \\
\hline
\end{tabular}

PIP, proximal interphalangeal; ROM, range of motion; QuickDASH, Quick Disabilities of Arm, Shoulder \& Hand.

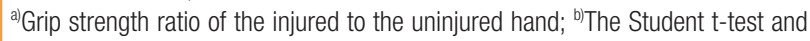
the Mann-Whitney U test.

extension lag between the groups $\left(8.1^{\circ}\right.$ vs. $\left.18.3^{\circ}, \mathrm{P}=0.035\right)$. No statistically significant differences were noted for flexion $\left(82.0^{\circ}\right.$ vs. $70.4^{\circ}$, respectively, $\mathrm{P} \geq 0.05$ ), grip-strength ratio (injured finger vs. corresponding contralateral finger; 0.897 vs. 0.831$)$, and QuickDASH score (23.0 vs. 32.6).

As shown in Table 4, no significant differences were seen in ROM, degree of flexion, and extension lag according to the size of the flap (maximum length of flap $\geq 3 \mathrm{~cm}$ or $<3 \mathrm{~cm}$ ) and the presence of concomitant fractures or flexor tendon ruptures. However, significant differences were found between patients who initiated rehabilitation after or within 30 days postoperatively in the PIP joint active $\mathrm{ROM}\left(54.6^{\circ}\right.$ vs. $\left.72.9^{\circ}, \mathrm{P}=0.03\right)$ and extension lag $\left(15.0^{\circ}\right.$ vs. $\left.10.8^{\circ}, \mathrm{P}=0.035\right)$.

Furthermore, no statistically significant differences were observed according to age or the timing of surgery (primary or delayed reconstruction). The average age of the patients who re- ceived arterial free flaps and venous free flaps was 39.2 and 33.4 years, respectively $(P=0.376)$, and rehabilitation started earlier in the arterial free flap group than in the venous free flap group (22.6 days vs. 31.8 days, $\mathrm{P}=0.022$ ).

\section{Cases}

\section{Case 1: Arterial free flap (second toe plantar free flap)}

A 19-year-old man sustained soft tissue contracture on the volar side of the PIP joint of his right ring finger after flexor tendon tenorrhaphy. The contracted tissue was excised and soft tissue coverage for the defect measuring $2.5 \times 1.5 \mathrm{~cm}$ was needed. Therefore, a second toe plantar free flap from the right foot was performed (Fig. 5). The flap survived, and the patient was discharged on postoperative day 21. At a 34-month follow-up, the patient showed painless active motion of the PIP joint $\left(10^{\circ}-100^{\circ}\right.$ active ROM), symmetric grip strength, and no donor site morbidity.

\section{Case 2: Venous free flap}

A 27-year-old man sustained a soft tissue defect on the volar side of the PIP joint of his left index finger caused by a drill. There were no concomitant fractures or flexor tendon ruptures. Emergency surgery was performed on the day of the injury. Soft tissue coverage was performed using a venous free flap from the left forearm (Fig. 6). The flap survived, and the patient was discharged on postoperative day 21 . At a 7 -month follow-up, the patient showed painless active motion of the PIP joint $\left(15^{\circ}-80^{\circ}\right.$ active ROM), symmetric grip strength, and no donor site morbidity. 
Table 4. Comparison of surgical outcomes according to the size of the flap, timing of rehabilitation and reconstruction, and concomitant fracture or flexor tendon rupture $(n=25)$

\begin{tabular}{|c|c|c|c|c|c|c|}
\hline Variable & PIP joint active ROM $\left({ }^{\circ}\right)$ & P-value & Flexion $\left({ }^{\circ}\right)$ & P-value & Extension lag $\left({ }^{\circ}\right)$ & P-value \\
\hline Maximum flap length & & 0.631 & & 0.875 & & 0.739 \\
\hline Maximum length $\leq 3 \mathrm{~cm}(n=14)$ & 68.0 & & 79.5 & & 11.5 & \\
\hline Maximum length $>3 \mathrm{~cm}(\mathrm{n}=11)$ & 64.0 & & 78.0 & & 14.0 & \\
\hline Fracture & & 0.331 & & 0.230 & & 0.778 \\
\hline Presence of fracture $(n=12)$ & 61.7 & & 72.8 & & 11.1 & \\
\hline Absence of fracture $(n=13)$ & 69.5 & & 83.6 & & 14.1 & \\
\hline Flexor tendon rupture & & 0.971 & & 0.579 & & 0.190 \\
\hline Presence of flexor tendon rupture $(n=12)$ & 65.5 & & 76.0 & & 10.5 & \\
\hline Absence of flexor tendon rupture $(n=13)$ & 66.5 & & 81.5 & & 15.0 & \\
\hline Timing of rehabilitation (POD) & & 0.03 & & 0.32 & & 0.035 \\
\hline POD $\geq 30$ days $(n=13)$ & 54.6 & & 69.6 & & 15.0 & \\
\hline POD $<30$ days $(n=12)$ & 72.9 & & 83.7 & & 10.8 & \\
\hline Timing of reconstruction (primary or delayed) & & 0.971 & & 0.615 & & 0.62 \\
\hline Primary reconstruction $(n=18)$ & 65.0 & & 77.5 & & 12.5 & \\
\hline Delayed reconstruction $(n=7)$ & 59.3 & & 73.6 & & 14.3 & \\
\hline
\end{tabular}

\section{Fig. 5. Case 1: Second toe plantar free flap}

(A) Soft tissue contracture on the volar side of the proximal interphalangeal (PIP) joint of his right ring finger. (B, C) The active range of motion (ROM) of the PIP joint was $45^{\circ}-75^{\circ}$ and that of the distal interphalangeal (DIP) joint was $25^{\circ}-30^{\circ}$. (D) After the excision of contracted tissue, a $2.5 \times 1.5 \mathrm{~cm}$ defect on the volar side of the PIP joint was covered with a second toe plantar free flap. (E, F) At a 34-month follow-up, the PIP joint active ROM was $10^{\circ}-100^{\circ}$ and the DIP joint active ROM was $30^{\circ}-35^{\circ}$.
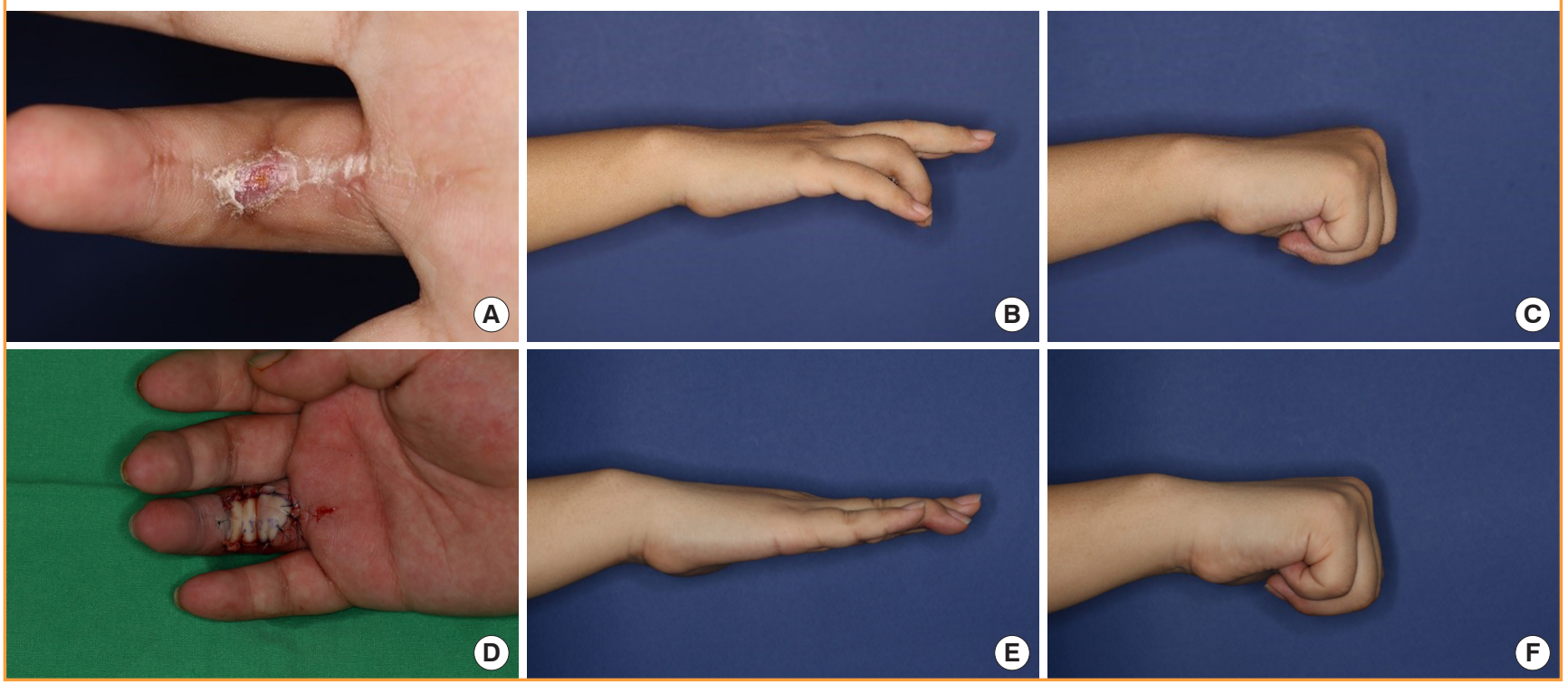

\section{DISCUSSION}

This study compared the surgical outcomes of venous free flaps and arterial free flaps in the coverage of volar soft tissue defects of the PIP joint. We found more favorable results for PIP joint active ROM and extension lag in arterial free flaps. Ours is the first study to compare surgical outcomes such as PIP joint active ROM, extension lag, grip strength, and QuickDASH scores be- tween these two types of free flaps in this region.

The palmar aspect of the fingers has thick glabrous and sensitive skin and fibrous septa that firmly anchor it to the periosteum against external pressure and shear forces. A volar defect of the PIP joint may expose structures such as the neurovascular bundle, flexor tendons, and bone; furthermore, such defects may cause scar contracture that can lead to disability in daily life $[5,6]$.

Some simple and commonly used coverage methods of skin 


\section{Fig. 6. Case 2: Venous free flap}

(A) A $3.0 \times 1.5 \mathrm{~cm}$ defect on the volar side of the proximal interphalangeal (PIP) joint without fracture or tendon rupture. (B) Soft tissue coverage with venous free flap from the volar side of the mid-forearm. (C) At a 7-month follow-up, a good contour with only a minimal scar was visible. $(D, E)$ At the 7-month follow-up, the PIP joint range of motion was $15^{\circ}-80^{\circ}$.
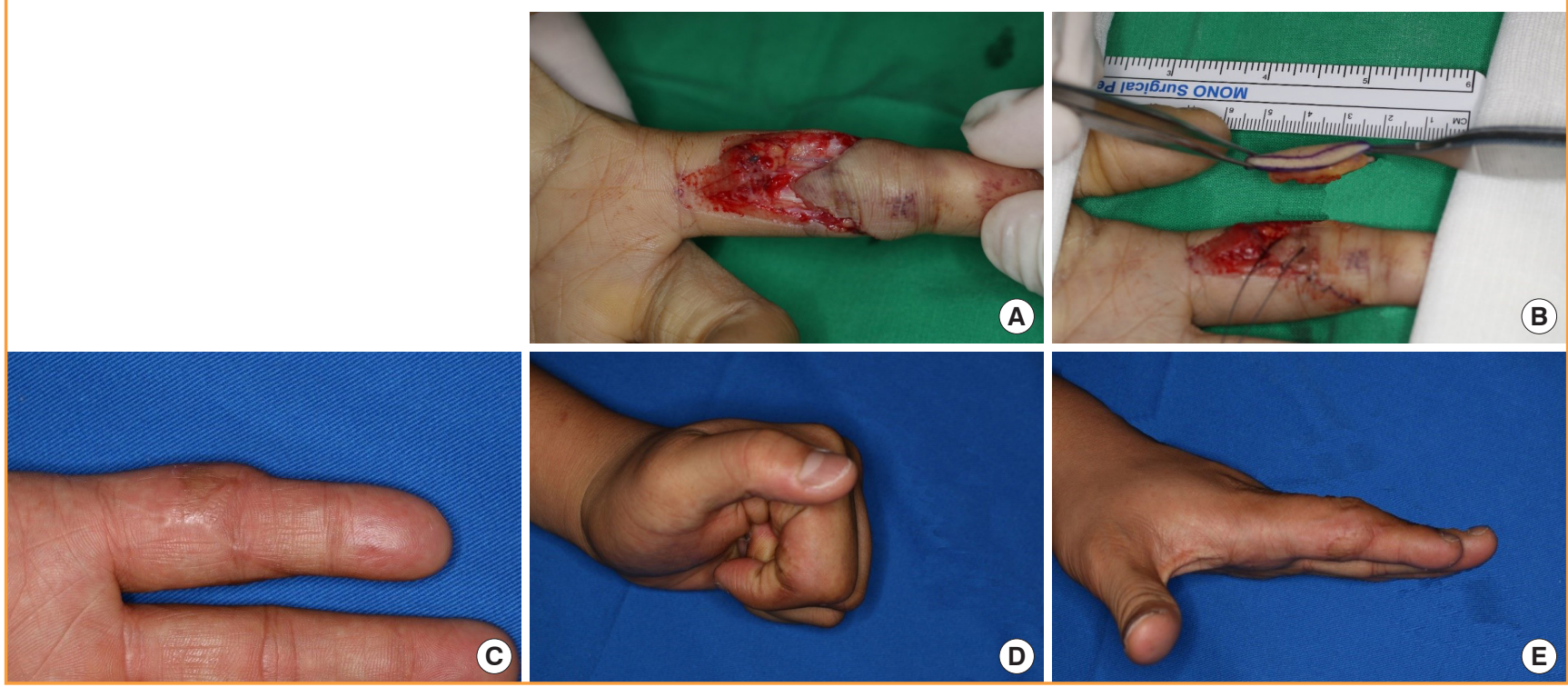

defects, such as secondary intention healing or skin grafts, are not viable options for the palmar side of the fingers. Secondary intention healing is a noninvasive method, but it may cause wound contracture, it involves a prolonged course of treatment, and it carries the risk of infection. A skin graft could avoid technically more challenging procedures, but it does not provide sufficient tissue for tendon gliding and cannot withstand external pressure and shear force [21].

Therefore, local, regional, or free flaps are the most practical reconstructive methods for volar surface defects of the PIP joint. In choosing the best flap method, the size, location, and skin characteristics of the defect should be considered, as well as the preferences and circumstances of both the surgeon and patient. Local and regional flaps do not involve any more complicated or difficult techniques, such as microsurgery, and have reliable circulation because they maintain their vascular supply. Therefore, they remain the treatment of choice before free tissue transfer is considered [22].

Although there are numerous types of local and regional flaps, only a few, such as the cross-finger flap, dorsal metacarpal artery flap, and advancement flap, can be utilized for covering volar defects of the PIP joint. Furthermore, because of their limitations in size and flap advancement, these flaps are difficult to use in large defects or in hard-to-reach locations. Furthermore, crossfinger flaps have a long immobilization period, which may lead to joint stiffness and require secondary surgery for division of the flap.
Therefore, free flaps should be considered in large or inaccessible defects and in patients who require short immobilization or early mobilization, such as children and elderly patients. Although free flaps present technical challenges, their advantages include flexibility in terms of donor site and size and being freely transferable and adaptable based on the preferences and circumstances of the surgeon and patient.

Compared with conventional free flaps, venous free flaps have the advantages of being thin, pliable, and easy and quick to dissect, while showing low donor site morbidity since no main arteries have to be sacrificed $[14,15]$. However, they are often aesthetically unsatisfactory because their color and characteristics are different from the skin at the recipient site. Their uncertain circulation may cause partial necrosis, which may require further operations and result in skin contracture [23]. In our study, five of the 12 patients were concerned about scarring and the color of their fingers, and four of the 12 patients required additional operations such as debridement, a skin graft, and a local flap.

Arterial free flaps possess a reliable physiological blood supply. The second toe plantar, thenar, and hypothenar free flaps are choices when reconstructing a volar PIP joint defect.

Of these three types of flaps, second toe plantar free flaps have the most similar characteristics to the skin of the volar side of the fingers. They are sensate, glabrous, durable, and of similar color. However, the size of these flaps is limited, making them unsuitable for large soft tissue defects. Furthermore, they require skin grafting at the donor site and additional anesthesia for 
harvesting on the foot $[1,18]$. In two of the three second toe plantar free flap cases, skin grafts from the medial plantar side of the same foot were needed to cover the defect in the donor site.

Thenar free flaps also have similar skin properties to those of the volar side of the PIP joint and can be innervated by the palmar cutaneous branch of the median nerve, if necessary $[4,12,19]$. Moreover, relatively large flaps can be harvested. The anatomical location is generally consistent, but the course of the vessels and the size of the flap are variable. It should be kept in mind that the scar at the donor site is relatively large and easily visible. In our study, two of the seven patients complained about a visible scar at the donor site.

Hypothenar free flaps, like thenar free flaps, have skin characteristics similar to those of the volar finger side and uncomplicated anatomy, and they can be harvested in the same operating field. These flaps show partial sensory recovery during longterm follow-up, but since there is no constant nerve branch, full sensory recovery should not be expected. In addition, the small diameter of the vessels could present considerable technical difficulties during microanastomosis.

The choice of the best free flap can be very difficult, especially in volar-side defects of the PIP joint, because each option has clear advantages and disadvantages. While consideration should be given to the preferences and circumstances of the surgeon and patient, ultimately, the surgical outcomes - that is, the recovery of function and patient satisfaction-are the most important aspects.

In our study, both groups showed relatively good results for flexion, QuickDASH score, and the grip-strength ratio of the injured to the uninjured hand. However, PIP joint active ROM and extension lag were more favorable in patients who received arterial flaps than in those who received venous free flaps.

This result may be explained in terms of the anatomical differences between the flaps. Venous free flaps are nourished by their venous network, but the exact vascular supply and mechanism of flap survival are unknown $[14,15]$. The uncertain and unstable supply may result in venous congestion, tissue swelling, minor tissue necrosis, and contracture $[23,24]$. As a result, the dimensions of these flaps diminished over time and the pliability and flexibility of the flap tissue seemed to be reduced. This study analyzed a small group of patients, but the proportion of partial necrosis in the venous free flap group was $42 \%(5 / 12)$, which was higher than that in the arterial free flap group (15\%, $2 / 13$ ). Furthermore, arterial free flaps using plantar, thenar, or hypothenar glabrous skin with fibrous septa firmly anchor the skin to the periosteum against external pressure and shear forces, potentially resulting in better long-term functional outcomes.

This study has several limitations. First, since the sample size was small, the significance of our statistical analysis was limited. Second, the findings of this study may have been affected by bias stemming from its retrospective comparative design. Therefore, in the future, prospective randomized studies should be conducted with larger numbers of patients. Third, there were very few cases with soft tissue defects only, so we had to include cases with fractures or flexor tendon rupture. Therefore, the results might have differed depending on these factors, rather than the type of free flap used. Nonetheless, based on our results, the surgical outcomes of cases with fractures or flexor tendon ruptures $(n=12$, respectively) showed no statistically significant differences compared to those with no fracture or flexor tendon rupture $(\mathrm{P} \geq 0.05)$. Therefore, this concern turned out not to be valid.

In addition, other factors that could influence the results rather than the type of surgery were analyzed. No statistically significant differences were observed according to age or timing of the surgery (primary or delayed reconstruction). Rehabilitation started earlier in patients who received arterial free flaps than in those who received venous free flaps. Significant differences were also found in the PIP joint active ROM and extension lag according to whether patients-initiated rehabilitation after or within 30 days postoperatively. Since the proportion of patients who received a skin graft due to partial flap necrosis was markedly higher in the venous free flap group (5/12 vs. $2 / 13$ in the arterial free flap group) and in those who received late rehabilitation (5/13 vs. $2 / 12$ in those who initiated rehabilitation within 30 days), the late rehabilitation of venous free flaps, which had a high proportion of partial necrosis in the flap skin, may have influenced the functional outcomes. However, future studies are needed to clarify this relationship definitively.

In summary, if microsurgical reconstruction of volar defects of the PIP joint is needed, arterial free flaps, such as the second toe plantar free flap, thenar free flap, and hypothenar free flap, are recommended treatment choices that yield good functional outcomes.

\section{NOTES}

\section{Conflict of interest}

No potential conflict of interest relevant to this article was reported.

\section{Ethical approval}

The study was approved by the Institutional Review Board of Gwangmyeong Sungae Hospital (IRB No. KIRB-2018-N-001) and performed in accordance with the principles of the Declaration of Helsinki. Written informed consents were obtained. 


\section{Patient consent}

The patients provided written informed consent for the publication and the use of their images.

\section{Author contribution}

Conceptualization: KJ Lee, MS Choi, SY Roh, SH Koh, JS Kim, DC Lee, MK Hong. Data curation: KJ Lee, MS Choi. Formal analysis: SY Roh. Methodology: KJ Lee, MS Choi, SY Roh, SH Koh, JS Kim, DC Lee, MK Hong. Project administration: KJ Lee, SY Roh, SH Koh, JS Kim, DC Lee, MK Hong. Visualization: KJ Lee, MS Choi, SY Roh, SH Koh, JS Kim, DC Lee, MK Hong. Writing - original draft: KJ Lee, MS Choi. Writing - review \& editing: KJ Lee, MS Choi.

\section{ORCID}

Min Suk Choi

Si Young Roh

Sung Hoon Koh

Jin Soo Kim

Dong Chul Lee

Kyung Jin Lee

Min Ki Hong https://orcid.org/0000-0002-8625-6124 https://orcid.org/0000-0002-8094-2561 https://orcid.org/0000-0003-3369-2974 https://orcid.org/0000-0003-4211-6901 https://orcid.org/0000-0002-9448-8291 https://orcid.org/0000-0002-8587-7420 https://orcid.org/0000-0003-0411-7006

\section{REFERENCES}

1. Cho YJ, Roh SY, Kim JS, et al. Second toe plantar free flap for volar tissue defects of the fingers. Arch Plast Surg 2013; 40:226-31.

2. Leibovic SJ, Bowers WH. Anatomy of the proximal interphalangeal joint. Hand Clin 1994;10:169-78.

3. Mansat MF. Volar aspect of the proximal interphalangeal joint: an anatomical study and pathological correlations. Bull Hosp Jt Dis Orthop Inst 1984;44:309-17.

4. Iwuagwu FC, Orkar SK, Siddiqui A. Reconstruction of volar skin and soft tissue defects of the digits including the pulp: experience with the free SUPBRA flap. J Plast Reconstr Aesthet Surg 2015;68:26-34.

5. Bain GI, Polites N, Higgs BG, et al. The functional range of motion of the finger joints. J Hand Surg Eur Vol 2015;40: 406-11.

6. Hume MC, Gellman H, McKellop H, et al. Functional range of motion of the joints of the hand. J Hand Surg Am 1990;15:240-3.

7. Rehim SA, Chung KC. Local flaps of the hand. Hand Clin 2014;30:137-51.

8. Cohen BE, Cronin ED. An innervated cross-finger flap for fingertip reconstruction. Plast Reconstr Surg 1983;72:68897.
9. Okazaki M, Hasegawa H, Kano M, et al. A different method of fingertip reconstruction with the thenar flap. Plast Reconstr Surg 2005;115:885-8.

10. Lai-jin L, Xu G. The reverse dorsal metacarpal flap: experience with 153 cases. Ann Plast Surg 2006;56:614-7.

11. Foucher G, Boulas HJ, Braga Da Silva J. The use of flaps in the treatment of fingertip injuries. World J Surg 1991;15: 458-62.

12. Kamei K, Shimada K, Kimura T, et al. Substantial volar defects of the fingers treated with free thenar flaps. Scand J Plast Reconstr Surg Hand Surg 1997;31:87-90.

13. Kim KS, Kim ES, Hwang JH, et al. Fingertip reconstruction using the hypothenar perforator free flap. J Plast Reconstr Aesthet Surg 2013;66:1263-70.

14. Yan $\mathrm{H}$, Zhang F, Akdemir O, et al. Clinical applications of venous flaps in the reconstruction of hands and fingers. Arch Orthop Trauma Surg 2011;131:65-74.

15. Yan H, Brooks D, Ladner R, et al. Arterialized venous flaps: a review of the literature. Microsurgery 2010;30:472-8.

16. Shim JH, Roh SY, Kim JS, et al. Normative measurements of grip and pinch strengths of 21st century korean population. Arch Plast Surg 2013;40:52-6.

17. Lee DC, Kim JS, Roh SY, et al. Flap coverage of dysvascular digits including venous flow-through flaps. Hand Clin 2019; 35:185-97.

18. Kimata Y, Mukouda M, Mizuo H, et al. Second toe plantar flap for partial finger reconstruction. Plast Reconstr Surg 1998;101:101-6.

19. Yang JW, Kim JS, Lee DC, et al. The radial artery superficial palmar branch flap: a modified free thenar flap with constant innervation. J Reconstr Microsurg 2010;26:529-38.

20. Han HH, Choi YS, Kim IB, et al. A perforator from the ulnar artery and cutaneous nerve of the hypothenar area: an anatomical study for clinical application. Microsurgery 2017; 37:49-56.

21. McGregor IA. Flap reconstruction in hand surgery: the evolution of presently used methods. J Hand Surg Am 1979;4: $1-10$.

22. Rockwell WB, Lister GD. Soft tissue reconstruction: coverage of hand injuries. Orthop Clin North Am 1993;24:41124.

23. De Lorenzi F, van der Hulst RR, den Dunnen WF, et al. Arterialized venous free flaps for soft-tissue reconstruction of digits: a 40-case series. J Reconstr Microsurg 2002;18:56974.

24. Tuffaha SH, Lee WPA. Treatment of proximal interphalangeal joint contracture. Hand Clin 2018;34:229-35. 